of investigations evaluating mucous transport in the respiratory tract using radionuclides. This chapter is also fairly detailed, and an extensive bibliography on the subject is provided (141 citations). These chapters should be of interest primarily to those working in the particular area being discussed.

Overall, the text has segments that should prove to be quite valuable to the practicing chest physician and resident in chest medicine. Other parts should prove to be of value to those investigating pulmonary pathophysiology or to residents in nuclear medicine. The text appears to be fairly well written and the illustrations are of good quality. There are several minor errors in labeling of the illustrations, but this should not detract from the overall value of the text.

M. Zelefsky

\title{
Books Received for Review
}

Respiratory and Infectious Disease (Profiles of Health and Disease in America Series). By Wrynn Smith. New York: Facts on File, 1987. 226 pp. US $\$ 35.00$.

\section{Errata}

Lung 165:341-351, 1987

Effects of Posture on Ventilation and Breathing Pattern During Room Air Breathing at Rest

The correct spelling of Dr. Jaeger's name is Marc J. Jaeger, with a "c" instead of a ' $\mathrm{k}$ '.

Lung 166:64

1987 Referees

Please note that several of the European referees' names were misspelled. The correct spellings are presented below:

Priv. Doz. Dr. Zach

Priv. Doz. Dr. Chowanetz

Prof. Dr. Müller

Prof. Dr. K. S. Kerrebijn

We apologize for these errors. 